\title{
Videothoracoscopic lobectomy: first year of experience in a single center
}

\author{
A Gonfiotti", D Barale, MO Jaus, F Montinaro, F Mannini \\ From 23rd World Congress of the World Society of Cardio-Thoracic Surgeons \\ Split, Croatia. 12-15 September 2013
}

\section{Background}

The purpose of this work is to evaluate the feasibility, safety and oncological appropriateness of a completely videothoracoscopic surgical program of major pulmonary resections (VATS-L) in a single center, in its first year of development.

\section{Methods}

From April 2012 to date, we performed 42 completely thoracoscopic lobectomies (non rib-spreading) with anterior approach to the pulmonary hilum. Clinical stages I were included and T3 or T4 tumors, central tumors, cN1-N2, previous ipsilateral thoracotomy were excluded. Whenever possible, we have obtained a preoperative diagnosis with CT-guided needle biopsy $(\mathrm{n}=$ $35,83 \%$ ); otherwise lobectomy was preceded by atypical resection and extemporaneous examination. A preoperative mediastinoscopy was performed following the guidelines of the National Comprehensive Cancer Network, $2013(\mathrm{n}=18,43 \%)$, in the same operative time with extemporaneous examination of the lymph nodes. Lung resection was always associated with a lymphadenectomy of at least 4 ilo-mediastinal stations.

\section{Results}

We treated 22 females and 20 males (mean age 71 years, range 54-82) in which we performed: right upper lobectomy $\mathrm{n}=10, \mathrm{n}=12$, left upper lobectomy, middle lobectomy $\mathrm{n}=4$, right lower lobectomy $\mathrm{n}=9$ and left lower lobectomy $n=7$. The main number of lymph nodes taken was 5.8 (range: 4-9). In 4 cases (9\%) it was necessary to convert the procedure, in 3 cases for minor arterial lesions and in one case for venous injury. The mean operative time was 150 minutes (range 90-270). The histopathologic examination revealed a $\mathrm{N} 1$ disease in

* Correspondence: agonfiotti@hotmail.com

Thoracic Surgery Division, Careggi University Hospital, Florence, Italy
5 cases $(12 \%)$ and in 1 case $\mathrm{N} 2(2 \%)$. The main time of hospitalization was 5 days (range: 3-8). We did not record cases of 30-day mortality.

\section{Conclusions}

On the basis of the results of this first year of experience in a single center, VATS-L appears to be a safe and effective alternative to traditional surgery even in the initial phase of a program of development of this technique.

Published: 11 September 2013

doi:10.1186/1749-8090-8-S1-0223

Cite this article as: Gonfiotti et al:: Videothoracoscopic lobectomy: first year of experience in a single center. Journal of Cardiothoracic Surgery 2013 8(Suppl 1):O223.
Submit your next manuscript to BioMed Central and take full advantage of:

- Convenient online submission

- Thorough peer review

- No space constraints or color figure charges

- Immediate publication on acceptance

- Inclusion in PubMed, CAS, Scopus and Google Scholar

- Research which is freely available for redistribution
C Biomed Central

\section{Biomed Central}

